\title{
Self, Identities and Medicine
}

\author{
Kristin Zeiler
}

Published online: 31 March 2009

(C) Springer Science+Business Media, LLC 2009

Many have described how illness, disorder or injury has made them not only undergo medical testing procedures in order to find out what was wrong with their bodies, but also made them question their way of being in the world as selves, including their identity. Such is the case when some organ receivers explain that they "are no longer themselves" after transplantation, since they have someone else's organ in their bodies [2, 5]. Such is also the case when Lance Armstrong [1, p. 14] describes how he, when given a testicular cancer diagnosis, engaged in a thorough questioning of "everything: my world, my profession, my self". He describes how he had left his home, heading towards the hospital as an "indestructable 25-year-old, bulletproof", and how the diagnosis changed "everything" [1, p. 14]. Many more examples can be given of how illness, disorder or injury can make us question who we are, our sense of self. Illness, disorder or injury can prompt us to engage in meaning-making processes as regards our selfunderstanding, who we are in relation to others and the world.

As individuals, we are part of the world of immediate experience. We interpret the world against the backdrop of our own unique situation, and this situation is part of others' situations. We engage in intersubjective meaning-making. A concern with such meaning-making in encounters in medicine implies a focus on the interplay between how I, as an individual, experience bodily changes such as those brought about by illness, disorder or injury in interactions with others and the world. This theme lies at the heart of several of the contributions to this issue on Self, Identities and Medicine.

This issue explores meaning-making and the relation between self, others and the world in patient-professional encounters where medical technology or therapy is offered or used. It also explores cultural constructions of identities. It investigates

K. Zeiler $(\bowtie)$

Division of Health and Society, Department of Medical and Health Sciences, Linköping University,

Linköping, Sweden

e-mail: kristin.zeiler@liu.se 
stigmatising and destigmatising potentials of certain medical diagnoses. A variety of topics are analysed, ranging from experiences of chronic pain, to identity-forming processes in transplantation, to images of ideal masculinity in Viagra advertisements, to the (possibly) destigmatising potential of the term "disorder of sex development" instead of "intersex condition". The contributions also share certain assumptions. The self is understood as more than a conscious "thinking thing" as John Locke [4, p. 80] once put it. The self is embodied and in order to explore what it means to be a self, we need to explore what it means to have a particular body and to live in a particular socio-cultural setting. Furthermore, many of the articles share an interest in how the lived body can be reduced to a body-part, a diagnosis or pain, as well as how such reduction can be resisted. Some of the articles also indicate how a concern with intersubjective meaning-making can be used in normative discussions of specific issues such as advanced directives.

Three of the articles draw on the work of the French phenomenologist Maurice Merleau-Ponty. Such is the case when Jennifer Bullington analyses how persons with chronic disease find themselves in a medical praxis that tends to conceptualise their bodies as bodies of the natural sciences, as "objects". In this praxis, their experiences of chronic disease risk being reduced to medical symptoms. Bullington argues for the importance of another way of conceptualising ill health. This alternative approach focuses on how the experience of chronic pain can disrupt the embodied self's relation to the world. The body can no longer "dis-appear" from our attention: we must attend, constantly, to our body in pain and we can no longer live the world as before. The mind-body-world harmony is broken and the body "dys-appears" to us: it appears to us as "bad" or "ill" [3, p. 85].

Bullington argues that the experience of pain may result in loss of identity. The self feels detached from things that previously gave meaning, feels detached from the world. This matters, she emphasises, for rehabilitation. In rehabilitation, Bullington argues, it is crucial to enable the experience of the embodied self as being more than a self in pain. Ideally, rehabilitation should help the patient in such a way that the body can, again, disappear from her or his attention. Bullington explores how this can take place.

A Merleau-Pontean framework is also discussed by Kristin Zeiler. She explores the role of the body for human subjectivity and intersubjectivity in Merlean-Pontean thinking, in the context of human hand allograft recipients' gradual experience of their new hand as theirs. She also examines Drew Leder's phenomenologically based ethics of organ donation and organ sale. Leder explores how phenomenology can help us understand the role of the body for human interconnectedness. This interconnectedness, Leder holds, is a reason why we cannot claim full ownership of our bodies and why we are not entitled to sell our bodies or body-parts. We may, however, give away a body-part as in organ donation. While sharing Leder's emphasis on human interconnectedness, Zeiler argues that two different conceptions of mineness are mixed: mineness as in "my way of engaging with the world" or in "my habitual point of view" and mineness as in "my possession". She also elaborates on another line of reasoning, that draws on Merleau-Ponty and Leder and that allows us to argue against some kinds of organ sale. 
While many medical therapies and treatments can result in self-identity issues for patients, the case of face transplantation has been said to evoke particularly crucial ones. Our faces are crucial mediums of communication; they matter to our selfidentity in a different way than do organs such as kidneys or livers.

This thread is elaborated upon by Andrew Edgar in his analysis of face transplantation and intersubjective meaning-making. Edgar suggests that we need a theory of an embodied and social self in order to understand the benefits and the risks of face transplantation, both as regards the patients' personal identity and the impact on a societal level (after all, we live in a society that often express prejudice towards disability and disfigurement). Such a theory, Edgar holds, can be elaborated on the basis of the work of Merleau-Ponty and G. H. Mead. Both of these scholars help us to understand how our sense of self is dependent upon our interaction with others. Our selves are formed (through the occupation of multiple roles, and the resultant negotiation of the "me" and the "I") as we take on the attitudes or roles of others, beginning with the pre-linguistic gestures through which another individual responds to our own gestures.

For Merleau-Ponty and for Mead, the sense of self responds to changes in the other's perception of the self. Edgar explores the implications of this conception of selfhood for face transplantation. Furthermore, he argues, a narrative account of the self is needed in order for us to understand the effect of a face transplant on the recipient's sense of self.

Bullington, Zeiler and Edgar highlight the intersubjective dimension of how organ or body-part receivers experience themselves and their situation: the self engages in intersubjective meaning-making with others and this self-other interaction can have a strong impact on our self-identity. This is a topic that lingers also in Ellen K. Feder's contribution. Sex, Feder says, is perhaps the most conspicuous category of identity. Furthermore, the way many persons with so-called intersex conditions, i.e. conditions where the anatomical, gonadal and chromosomal sex is not typical for one sex, have been treated indicates the presence of strong cultural and dualistic, gendered bodily norms.

Feder identifies the idea that a person with an intersex condition is a certain "kind" of person as one of the keys to understanding the way such persons have been (mal)treated in medicine. This conception has motivated medical treatment that has too often resulted in harm to the subjects. Too often has the aim of medical treatment been "normal appearance" instead of a concern with the conequences of intersex conditions for the subject's health. Feder explores strengths and weaknesses in different ways of conceptualising children who are diagnosed with unclear sex. In particular, she investigates the US and European Endocrinological Societies' suggestion that "intersexual persons" or "hemaphrodites" should instead be referred to as people with "disorders of sex development". In Feder's view, the change in terminology can result in a shift from unclear sex being seen as "a condition like no other", to its being seen as "a condition like many others". This would be beneficial, provided that it results in less concern within medical praxis with how the child's sex should look in order to pass as "normal" and more concern with the health of the child. Feder also discusses the view of some patient groups who have reacted against the new medical terminology and who claims that they are 
not diseased, but rather have a gender identity as intersexuals. Making conditions that result in unclear sex into issues of identity, she suggests, has contributed to the view that these are conditions like no other and to the stigmatisation of the children and adults in question.

Several of the articles in this issue emphasise that identity-work takes place in close relation to cultural norms and ideals. This thread is particularly evident in Cecilia Åsberg and Ericka Johnson's analysis of the cultural construction of ideal masculinity. Åsberg and Johnson analyse a set of images at the Pfizer-sponsored website for potential Viagra costumers in Sweden. They explore the public image of masculinity, male sexual health and cultural tools for creating a pharmaceutical appeal at this website. This Viagra website, they argue, naturalises a hegemonic form of masculinity that is closely related to virility and to erectile capacity for penile penetration of the female body. Asberg and Johnson also contrast the Swedish Viagra website with websites in the US and New Zeeland. They show how the "Swedish Viagra man", i.e. the ideal consumer of Viagra, as he is addressed and imagined in texts and photos on this website, is presented as an able-bodied, physically active and free individual. The masculine identity on the Swedish Viagra website is also marked with national signifiers related to certain socioeconomic classes. By showing how this website draws on cultural imaginary of freedom, naturalness, wilderness and bright Swedish summer nights, Åsberg and Johnson highlight its focus on a Swedish, middle class sexuality and a naturalised white masculinity.

Finally, Silke Schicktanz contributes with an analysis of how the writing of an advanced directive can be seen as a matter of identity-work. She discusses whether advanced directives can be seen as instruments for self-interpretation and lifeplanning, whether the writing of an advanced directive can be seen as one step in a process of seeking a good life and a "good death". In Schicktanz' view, the writing of this document can be seen as a matter of identity-work: in deciding how one wants to die one also clarifies, to some extent, who one is. Since the self is always a cultural being, and since identity-formation takes place in close interaction with others, it is important to explore what person I am in relation to socio-cultural embeddings. This needs to be taken into account by third parties who seek to interpret the advanced directives. Schicktanz presents previous empirical research which compares major tendencies as regards decisions about advanced directives and the end of life in different countries and ethnic groups and she urges us to see differences within these groups.

Schicktanz also states that though not all of us may want to write advanced directives, better structures are needed in order to enable people to deliberate on whether they want to draft them.

Acknowledgments We are most grateful to the Swedish foundation Riksbankens Jubileumsfond and the Swedish Council for Working Life and Social Research for having financed a three-day event where the authors had the opportunity to present and discuss their papers. 


\section{References}

1. Armstrong, L. (2001). It's not about the bike: My journey back to life. London: Yellow Jersey Press (Armstrong is quoted Wainwright, P., \& Rapport, F. (2005). The nature of the self and how it is experienced within and beyond the health care setting. Medical Humanities, 31, 57-59).

2. Haddow, G. (2005). The phenomenology of death, embodiement and organ transplantation. Sociology of Health \& Illness, 27, 92-113. doi:10.1111/j.1467-9566.2005.00433.x.

3. Leder, D. (1990). The absent body. Chicago: The University of Chicago Press.

4. Locke, J. ([1690] 2001). An essay concerning human understanding. Kitchener: Batoche Books.

5. Sanner, M. A. (2000). Transplant recipients' conceptions of three key phenomena in transplantation: The organ donation, the organ donor, and the organ transplant. Clinical Transplantation, 17, 391-400. doi:10.1034/j.1399-0012.2003.00065.x. 